\title{
Contributions of asthma, rhinitis and IgE to exhaled nitric oxide in adolescents
}

\author{
Bess M. Flashner (1) ${ }^{1}$, Sheryl L. Rifas-Shiman², Emily Oken², \\ Carlos A. Camargo Jr (103,4, Thomas A.E. Platts-Mills ${ }^{5}$, Lisa Workman ${ }^{5}$, \\ Augusto A. Litonjua $\mathbb{1 0}^{6}$, Diane R. Gold ${ }^{3,7}$ and Mary B. Rice (1) ${ }^{1}$
}

Affiliations: 'Division of Pulmonary, Critical Care and Sleep Medicine, Dept of Medicine, Beth Israel Deaconess Medical Center, Boston, MA, USA. ${ }^{2}$ Division of Chronic Disease Research Across the Lifecourse, Dept of Population Medicine, Harvard Medical School and Harvard Pilgrim Health Care Institute, Boston, MA, USA. ${ }^{3}$ Channing Division of Network Medicine, Dept of Medicine, Brigham and Women's Hospital, Boston, MA, USA. ${ }^{4}$ Dept of Emergency Medicine, Massachusetts General Hospital, Boston, MA, USA. ${ }^{5}$ Dept of Allergy and Immunology, University of Virginia Health System, Charlottesville, VA, USA. ${ }^{6}$ Pediatric Pulmonary Division, Dept of Pediatrics, Golisano Children's Hospital at Strong, University of Rochester Medical Center, Rochester, NY, USA. ${ }^{7}$ Dept of Environmental Health, Harvard T.H. Chan School of Public Health, Boston, MA, USA.

Correspondence: Bess M. Flashner, Beth Israel Deaconess Medical Center, 330 Brookline Ave, Boston, MA, 02215, USA. E-mail: bflashnelabidmc.harvard.edu

ABSTRACT Exhaled nitric oxide fraction $\left(F_{\mathrm{eNO}}\right)$ is an indicator of allergic airway inflammation. However, it is unknown how asthma, allergic rhinitis (AR) and allergic sensitisation relate to $F_{\text {eNO}}$, particularly among adolescents and in overlapping conditions. We sought to determine the associations between asthma, AR, and aeroallergen immunoglobulin (Ig)E and $F_{\mathrm{eNO}}$ in adolescents.

We measured $F_{\text {eNO }}$ among 929 adolescents (aged 11-16 years) in Project Viva, an unselected prebirth cohort in Massachusetts, USA. We defined asthma as ever asthma physician diagnosis plus wheezing in the past year or taking asthma medications in the past month, AR as a physician diagnosis of hay fever or $\mathrm{AR}$, and aeroallergen IgE as any $\operatorname{IgE}>0.35 \mathrm{IU} \cdot \mathrm{mL}^{-1}$ among 592 participants who provided blood samples. We examined associations of asthma, $\mathrm{AR}$ and $\mathrm{IgE}$ with percent difference in $F_{\mathrm{eNO}}$ in linear regression models adjusted for sex, race/ethnicity, age and height, maternal education and smoking during pregnancy, and household/neighbourhood demographics.

Asthma (14\%) was associated with 97\% higher $F_{\mathrm{eNO}}$ (95\% CI 70-128\%), AR (21\%) with 45\% higher $F_{\text {eNO }}(95 \%$ CI $28-65 \%)$, and aeroallergen IgE (58\%) with $102 \%$ higher $F_{\text {eNO }}$ (95\% CI 80-126\%) compared to those without each condition, respectively. In the absence of asthma or AR, aeroallergen $\operatorname{IgE}$ was associated with $75 \%$ higher $F_{\mathrm{eNO}}\left(95 \%\right.$ CI 52-101), while asthma and AR were not associated with $F_{\mathrm{eNO}}$ in the absence of IgE.

The link between asthma and AR with $F_{\mathrm{eNO}}$ is limited to those with IgE-mediated phenotypes. $F_{\mathrm{eNO}}$ may be elevated in those with allergic sensitisation alone, even in the absence of asthma or AR.

@ERSpublications

While asthma, allergic rhinitis (AR) and allergic sensitisation are associated with higher $F_{\mathrm{ENO}}$, asthma and $A R$ in the absence of aeroallergen IgE are not associated with $F_{\mathrm{ENO}}$. When elevated in asthma or $\mathrm{AR}, F_{\mathrm{ENO}}$ suggests allergic sensitisation. https://bit.ly/3bGgr0r

Cite this article as: Flashner BM, Rifas-Shiman SL, Oken E, et al. Contributions of asthma, rhinitis and IgE to exhaled nitric oxide in adolescents. ERJ Open Res 2021; 7: 00945-2020 [https://doi.org/ 10.1183/23120541.00945-2020].

This article has supplementary material available from openres.ersjournals.com

Received: 16 Dec 2020 | Accepted after revision: 4 March 2021

Copyright $\odot$ The authors 2021. This version is distributed under the terms of the Creative Commons Attribution NonCommercial Licence 4.0. For commercial reproduction rights and permissions contact permissions@ersnet.org 


\section{Introduction}

Exhaled nitric oxide fraction $\left(F_{\mathrm{eNO}}\right)$ is an indicator of allergic airway inflammation and can aid in the diagnosis of allergic asthma [1]. The influence of concurrent allergic rhinitis (AR) and allergic sensitisation to environmental allergens on $F_{\mathrm{eNO}}$ measurements is not well-known in adolescents. How each of these (asthma, AR and aeroallergen immunoglobulin (Ig)E) relate to $F_{\mathrm{eNO}}$ is important not only for interpretation of $F_{\mathrm{eNO}}$ in clinical use but also for a greater understanding of the factors that lead to elevated $F_{\mathrm{eNO}}$. We sought to understand the associations of asthma, AR, and aeroallergen IgE with $F_{\mathrm{eNO}}$ in an adolescent population.

Asthma and AR are common and contribute to significant morbidity, with poorer quality of life, missed days of school, healthcare costs and emergency room visits for asthma exacerbations, resulting from difficulty sleeping, fatigue, and changes in mood and cognition [2]. AR and asthma share epidemiological overlap. AR occurs in $>75 \%$ of patients with asthma, and asthma is seen in up to $40 \%$ of those with AR [3]. In those with both $\mathrm{AR}$ and asthma, $\mathrm{AR}$ may present first and there is a risk factor for subsequent development of asthma [4-7].

Asthma and AR are each known to be associated with elevated $F_{\mathrm{eNO}}$ in both adults and children. Nitric oxide $(\mathrm{NO})$ is an intercellular messenger known to mediate a variety of processes, including immune function and inflammation [8]. In the lung, $\mathrm{NO}$ acts as a signalling molecule in bronchial and vascular dilatation, ciliary kinesis, and neurotransmission in the non-adrenergic and non-cholinergic systems [9]. In allergic inflammation, T-helper- 2 cells, type 2 innate lymphoid cells, mast cells and eosinophils produce cytokines, like interleukin (IL)-4 and IL-13, with downstream effects including the activation of inducible NO synthase (iNOS) and thus elevated NO levels. Therefore, $F_{\mathrm{eNO}}$ is considered a marker of type 2 airway inflammation, which occurs with AR in the upper airway or allergic asthma in the lower airway [9-13]. Elevation of $F_{\mathrm{eNO}}$ may indicate not only allergic asthma or AR but also elevations in circulating $\operatorname{IgE}$ against environmental allergens. In previous work in this same Project Viva cohort, an unselected pre-birth cohort in Massachusetts, USA, we have found differences in the nasal epigenome in association with asthma, AR, aeroallergen $\operatorname{IgE}$ and $F_{\mathrm{eNO}}$ that are annotated with genes implicated in type 2 inflammatory responses [14]. Currently, the American Thoracic Society recommends $F_{\text {eNO }}$ in the diagnosis of eosinophilic airway inflammation, and suggests that it may be used to support the diagnosis of asthma where the diagnosis is less clear [1]. $F_{\text {eNO}}$, however, may also be elevated in AR or allergic sensitisation to environmental allergens $[15,16]$. Therefore, we sought to elucidate the contributors to $F_{\mathrm{eNO}}$ and supplement our understanding of its diagnostic utility. In this study, we examined the relationships of asthma, AR, and aeroallergen IgE with $F_{\mathrm{eNO}}$ in an adolescent population in Project Viva, a cohort not selected on the basis of asthma or allergy.

\section{Materials and methods}

Study design and participants

Between 1999 and 2002 we recruited women in early pregnancy into Project Viva from eight obstetric offices of Atrius Harvard Vanguard Medical Associates, a multi-specialty group practice in eastern Massachusetts. Exclusion criteria included multiple gestation, inability to answer questions in English, and gestational age $\geqslant 22$ weeks at recruitment. Details of recruitment and retention are available elsewhere [17]. Of the 2128 infants, we included in this analysis those participants with $F_{\text {eNO }}$ measurements at an in-person visit in early adolescence, which totalled 929. Compared with the 929 included participants, the 1199 excluded participants were less likely to have college-educated mothers (59\% versus 71\%) and more likely to have mothers who smoked during pregnancy (15\% versus $9 \%)$. However, maternal age at enrolment, gestational age at delivery, and sex and race/ethnicity were similar. Those 1199 were excluded due to either missing $F_{\mathrm{eNO}}$ or no early adolescent visit. The median adolescent age was 12.9 years with a range of 11.9-16.6 years; there were no participants older than this due to cohort inception dates.

\section{Asthma and AR}

We defined current asthma as a maternal report of ever asthma diagnosis plus wheeze symptoms in the past 12 months or use of asthma medications in the past month, reported on an early teen questionnaire in keeping with the Study of Asthma and Allergies in Childhood questionnaire [18]. We used as a comparison group with no asthma diagnosis, no wheezing and no use of asthma medications or wheezing in the past 12 months. Participants were defined as having AR if they reported ever receiving a physician diagnosis of hay fever or AR. Both current asthma and AR were reported by parental questionnaire at the early teen follow-up visit.

\section{Aeroallergen IgE}

Trained research phlebotomists collected blood from participants at the early teen visit, which we centrifuged and stored at $-80 \mathrm{C}$. We measured plasma IgE against Dermatophagoides farina (dust mite), 
cat or dog dander, Aspergillus fumigatus (mould), Alternaria alternata (plant fungi), common ragweed, oak, ryegrass, or silver birch. Allergen extract-specific IgE antibodies were measured by ImmunoCap (Thermo Fisher Scientific/Phadia, Kalamazoo, Michigan); a widely used in vitro sandwich immunoassay, as described previously $[19,20]$. We defined aeroallergen IgE as having IgE against any of these outdoor or indoor allergens $>0.35 \mathrm{IU} \cdot \mathrm{mL}^{-1}$. We defined "perennial IgE" as having $\mathrm{IgE}>0.35 \mathrm{IU} \cdot \mathrm{mL}^{-1}$ against any of the following: D. farina (dust mite), cat or dog dander, A. fumigatus (mould) or A. alternata (plant fungi). We defined "seasonal IgE" as having any $\operatorname{IgE}>0.35 \mathrm{IU} \cdot \mathrm{mL}^{-1}$ against any of the following: common ragweed, oak, ryegrass or silver birch.

\section{Measurement of $\mathrm{F}_{\mathrm{eNO}}$}

Exhaled NO levels were measured twice for each participant with a portable electrochemical device (NIOX MINO; Aerocrine AB); this has been validated by chemiluminescence technology, with an accuracy of $\pm 5 \mathrm{ppb}$ [21]. Prior to each measurement, participants breathed in through an NO scrubbing filter and exhaled into room air twice. This was done in keeping with prior studies using $F_{\mathrm{eNO}}$; the ambient air NO was not measured [22-24]. On the third breath, participants inhaled through the filter and exhaled into the $F_{\mathrm{eNO}}$ analyser. The last $3 \mathrm{~s}$ of the exhalation were utilised for $F_{\mathrm{eNO}}$ measurement; this ensures lower rather than upper airway measurement. Nose clips were not used.

\section{Statistical analysis}

Potential confounders were selected a priori, based on known or suspected associations with asthma or allergy. Model 1 adjusted for sex and age and height at the early teen visit. Model 2 additionally adjusted for race/ethnicity, maternal education and smoking during pregnancy, median value of owner-occupied housing and education (\% with a bachelor degree) based on census tract of home residence at time of mid-childhood visit from 2000, and household income and any smokers at home at the early teen visit. We additionally adjusted for body mass index in model 3.

We averaged the two $F_{\mathrm{eNO}}$ measurements and included the log-transformed value as a continuous outcome in linear regression models. We present effect estimates as \% change (95\% CI) in $F_{\text {eNO}}$, calculated as (exponentiated $(\beta)-1) \times 100$. In secondary analyses, we examined $F_{\mathrm{eNO}}$ in categories $(<20,20-\leqslant 35$ and $>35 \mathrm{ppb}$ ) based on American Thoracic Society guidelines [1] using multinomial logistic regression models. We examined the associations of asthma, AR, and aeroallergen IgE with $F_{\text {eNO }}$ using separate linear and logistic regression models. We repeated linear regression models for the associations of seasonal and perennial IgE with $F_{\mathrm{eNO}}$.

To examine associations of overlapping conditions of asthma, AR and aeroallergen IgE, we derived an eight-category exposure based on the combination of these three exposures. We ran linear regression models with this eight-category exposure and used no aeroallergen IgE, no AR, no asthma as the reference category. We performed all analyses using SAS 9.4 (SAS Institute).

\section{Results}

\section{Study population}

The characteristics of the 929 study participants included in any analysis and their mothers are shown in table 1. Reported smoking in the home was rare (12\%) and mean reported annual household income was $\$ 109000$. Children were predominantly white $(64 \%)$ and their average age was 13 years. Mean \pm SD $F_{\text {eNO }}$ was $26 \pm 27 \mathrm{ppb}$ and $19 \%$ of study participants had exhaled NO levels above the upper limit of normal for this age group (35 ppb) [1]

Overall, 115 (14\%) out of 797 participants reported asthma while 179 (21\%) out of 869 reported AR. Aeroallergen IgE >0.35 IU.mL $\mathrm{mL}^{-1}$ was detected in 345 (58\%) out of 592 of those providing blood samples with IgE results. Mean \pm SD $F_{\mathrm{eNO}}$ in those with asthma was $48.4 \pm 43.0 \mathrm{ppb}$ compared to $21.8 \pm 20.4 \mathrm{ppb}$ in those without asthma. Mean \pm SD $F_{\mathrm{eNO}}$ in those with AR was $35.7 \pm 32.8 \mathrm{ppb}$ compared to $23.5 \pm 24.9 \mathrm{ppb}$ without AR. Participants with aeroallergen IgE had mean \pm SD $F_{\mathrm{eNO}} 36.2 \pm 34.2 \mathrm{ppb}$ compared to $14.8 \pm 9.5 \mathrm{ppb}$ in those without $\mathrm{IgE}$.

Associations of each condition with $F_{\text {eNO }}$ are shown in table 2, where model 1 is parsimoniously adjusted and model 2 is fully adjusted, with similar results. Asthma was common in those with $F_{\mathrm{eNO}}>35 \mathrm{ppb} ; 35 \%$ of teens with $F_{\mathrm{eNO}}>35 \mathrm{ppb}$ had asthma versus $7 \%$ among participants with $F_{\mathrm{eNO}}<20 \mathrm{ppb}$ and $18 \%$ among participants with $F_{\mathrm{eNO}} 20-\leqslant 35 \mathrm{ppb}$. Of the three conditions, the presence of aeroallergen IgE and asthma diagnosis each had a similar association with $F_{\text {eNO}}$, while the magnitude of the association was half as great for AR. Specifically, those with asthma had a 97\% higher $F_{\mathrm{eNO}}$ (95\% CI 70-128\%) compared to those without asthma. Those with AR had a $45 \%$ higher $F_{\mathrm{eNO}}(95 \%$ CI 28-65\%) compared to those without AR, and those with aeroallergen IgE had 102\% higher $F_{\text {eNO }}(95 \%$ CI 80-126\%) compared to those without aeroallergen IgE. Perennial IgE was associated with $119 \%$ higher $F_{\mathrm{eNO}}(95 \%$ CI 97-144) while seasonal $\operatorname{IgE}$ 


\begin{tabular}{|c|c|}
\hline Subjects $\mathrm{n}$ & 929 \\
\hline \multicolumn{2}{|l|}{ Child } \\
\hline \multicolumn{2}{|l|}{ Sex } \\
\hline Male & $466(50)$ \\
\hline Female & $463(50)$ \\
\hline \multicolumn{2}{|l|}{ Race/ethnicity } \\
\hline Black & 154 (17) \\
\hline Hispanic & $40(4)$ \\
\hline Asian & $28(3)$ \\
\hline White & $593(64)$ \\
\hline Other or $>1$ race/ethnicity & 113 (12) \\
\hline \multicolumn{2}{|l|}{ Early teen visit } \\
\hline Age years & $13 \pm 1$ \\
\hline \multicolumn{2}{|l|}{ Age at visit years } \\
\hline 11.9 to $<13$ & 505 (54.4) \\
\hline 13.0 to $<15.0$ & $374(40.3)$ \\
\hline 15.0 to 16.6 & $50(5.4)$ \\
\hline Height cm & $160 \pm 9$ \\
\hline \multicolumn{2}{|l|}{ BMI percentile category $\%$} \\
\hline$<5$ th & 30 (3) \\
\hline $5-<85$ th & $634(68)$ \\
\hline$>85$ th & $262(28)$ \\
\hline Exhaled nitric oxide ppb & $26 \pm 27$ \\
\hline \multicolumn{2}{|l|}{ Exhaled nitric oxide } \\
\hline$<20 \mathrm{ppb}$ & $553(60)$ \\
\hline $20-\leqslant 35 \mathrm{ppb}$ & $196(21)$ \\
\hline$>35 \mathrm{ppb}$ & $180(19)$ \\
\hline \multicolumn{2}{|l|}{ Current asthma } \\
\hline No & $682(86)$ \\
\hline Yes & $115(14)$ \\
\hline \multicolumn{2}{|l|}{ Ever allergic rhinitis } \\
\hline No & $690(79)$ \\
\hline Yes & $179(21)$ \\
\hline \multicolumn{2}{|l|}{ Any aeroallergen $\lg E>0.35 \mathrm{kU} \cdot \mathrm{L}^{-1}$} \\
\hline No & $247(42)$ \\
\hline Yes & $345(58)$ \\
\hline Annual household income at early teen visit $\$ 1000$ & $109 \pm 44$ \\
\hline Any smokers at home at early teen visit & $114(12)$ \\
\hline \multicolumn{2}{|l|}{ Mother/family } \\
\hline \multicolumn{2}{|l|}{ Pregnancy smoking status } \\
\hline Never & $653(71)$ \\
\hline Former & $188(20)$ \\
\hline During pregnancy & $85(9)$ \\
\hline \multicolumn{2}{|l|}{ College graduate } \\
\hline No & 264 (29) \\
\hline Yes & $662(71)$ \\
\hline Median value owner-occupied housing $\$ 1000^{\#}$ & $263 \pm 149$ \\
\hline Percent with education higher than a bachelor's degree" & $42 \pm 20$ \\
\hline
\end{tabular}

Data are presented as $\mathrm{n}(\%)$ or mean $\pm \mathrm{SD}$, unless otherwise stated. BMI: body mass index; $\mathrm{lg}$ : immunoglobulin. ${ }^{\#}$ : based on census tract, mid-childhood.

was associated with $71 \%$ higher $F_{\mathrm{eNO}}$ (95\% CI 52-93). Similar results were seen in logistic regression analyses for the clinical thresholds of $F_{\mathrm{eNO}}$. Asthma was associated with eight times higher odds (95\% CI 5-14) of $F_{\mathrm{eNO}}>35 \mathrm{ppb}$, AR was associated with three times higher odds (95\% CI 2-5) of $F_{\mathrm{eNO}}>35 \mathrm{ppb}$ and aeroallergen IgE was associated with 28 times higher odds (95\% CI 12-63) of $F_{\mathrm{eNO}}>35 \mathrm{ppb}$ compared to those without each condition (table 2).

We found similar associations when stratified by sex (table S2). Since steroids can affect $F_{\text {eNO}}$, we ran a sensitivity analysis, excluding participants who used oral or inhaled corticosteroids within $72 \mathrm{~h}$ of $F_{\text {eNO }}$ testing $(\mathrm{n}=22)$ and found similar associations between asthma, AR and aeroallergen IgE with higher $F_{\text {eNO. }}$ 
TABLE 2 Associations of asthma, allergic rhinitis (AR) and aeroallergen immunoglobulin (lg)E with exhaled nitric oxide fraction $\left(F_{\text {eNO }}\right)$ using linear and multinomial logistic regression models

\begin{tabular}{|c|c|c|c|c|c|c|}
\hline & \multicolumn{3}{|c|}{ Model $1^{\#}$} & \multicolumn{3}{|c|}{ Model $2^{\text {ๆ }}$} \\
\hline & \multirow{2}{*}{$\begin{array}{l}\text { Linear regression } \\
\% \text { difference in } \\
F_{\text {eNo }}(95 \% \mathrm{CI}) \\
\end{array}$} & \multicolumn{2}{|c|}{$\begin{array}{c}\text { Logistic regression }^{+} \\
\text {OR }(95 \% \mathrm{CI})\end{array}$} & \multirow{2}{*}{$\begin{array}{l}\text { Linear regression } \\
\% \text { difference in } \\
F_{\text {eNO }}(95 \% \mathrm{CI})\end{array}$} & \multicolumn{2}{|c|}{$\begin{array}{l}\text { Logistic regression }^{+} \\
\text {OR }(95 \% \mathrm{CI})\end{array}$} \\
\hline & & $20-\leqslant 35 \mathrm{ppb}$ & $>35 \mathrm{ppb}$ & & $20-\leqslant 35 \mathrm{ppb}$ & $>35 \mathrm{ppb}$ \\
\hline Asthma versus no asthma & $97(73-124)$ & $3(2-5)$ & $8(5-13)$ & $97(70-128)$ & $3(1-5)$ & $8(5-14)$ \\
\hline \multicolumn{7}{|c|}{ 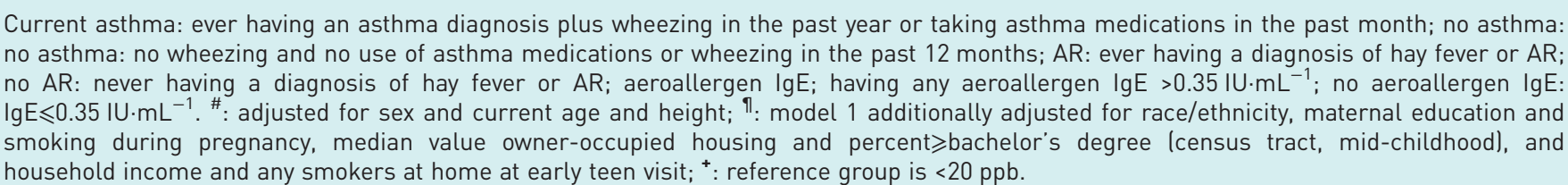 } \\
\hline
\end{tabular}

Finally, we adjusted for body mass index and found similar associations with asthma, AR and aeroallergen IgE with $F_{\text {eNO }}$ in both linear and logistic regression models (table S3).

Overlapping associations of allergy, asthma and aeroallergen IgE with $\mathrm{F}_{\text {eNO }}$

To examine associations of overlapping conditions of asthma, AR and aeroallergen IgE, we derived an eight-category exposure based on the combination of these three exposures among 476 participants with non-missing values for the three exposures. The reference category was no asthma, no AR and no aeroallergen IgE (figure 1, table S1). We found that, in the absence of asthma or AR, aeroallergen $\operatorname{IgE}$ alone $(n=173,36 \%)$ was associated with $75 \%$ higher $F_{\mathrm{eNO}}(95 \%$ CI $52-101 \%)$. Asthma in the absence of AR and aeroallergen $\operatorname{IgE}(n=10,2 \%), A R$ in the absence of asthma and aeroallergen $\operatorname{IgE}(n=14,3 \%)$, and asthma and $\mathrm{AR}$ in the absence of aeroallergen $\operatorname{IgE}(\mathrm{n}=6,1 \%)$ were uncommon and not associated with
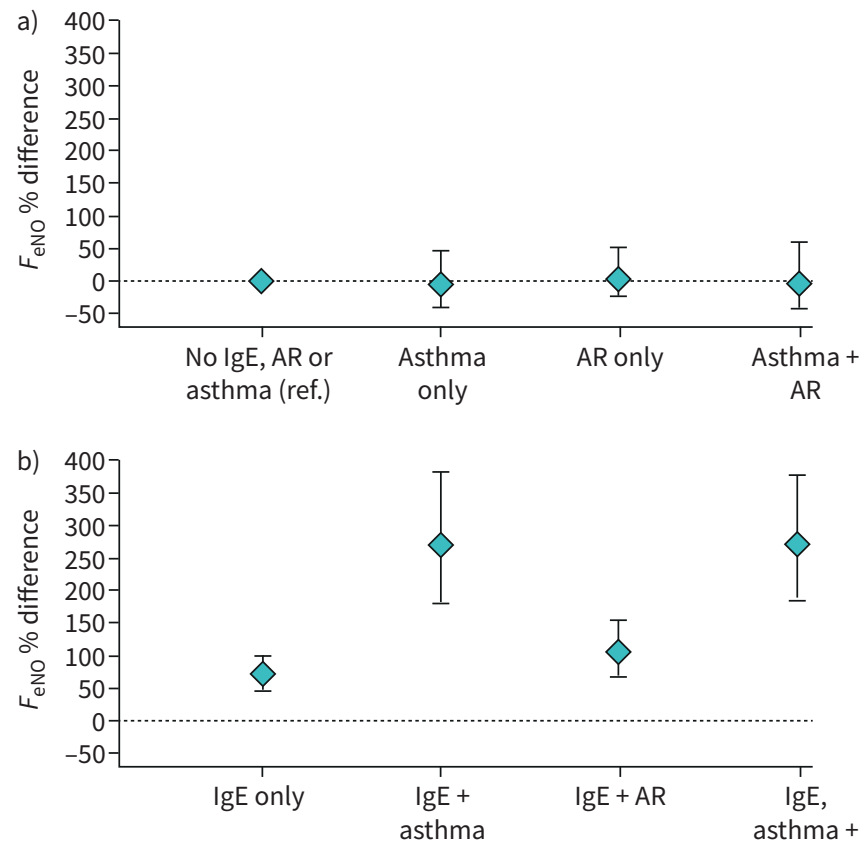

FIGURE 1 Percent difference in exhaled nitric oxide fraction $\left(F_{\mathrm{eNO}}\right)$ relative to reference group a) without detectable aeroallergen immunoglobulin (Ig)E and b) with aeroallergen IgE. AR: allergic rhinitis. 
$F_{\text {eNO }}$. The presence of all three exposures (asthma, AR and aeroallergen $\left.\operatorname{IgE}(\mathrm{n}=32,7 \%)\right)$ was associated with $272 \%$ higher $F_{\mathrm{eNO}}$ (95\% CI 189-379\%) compared to having none of these (figure 1).

\section{Discussion}

In this study of adolescents, we found, as expected, that asthma and allergy were each associated with

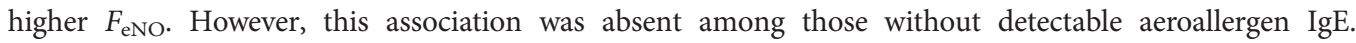
Additionally, aeroallergen IgE was associated with elevated $F_{\text {eNO }}$ even in the absence of asthma or AR.

The association between asthma and elevated $F_{\mathrm{eNO}}$ among adolescents in this study is consistent with the well-established connection between allergic asthma and airway inflammation as measured by $F_{\text {eNO }}$. Exhaled NO $>35 \mathrm{ppb}$ in children strongly supports the diagnosis of asthma and can be used as a diagnostic tool [1]. $F_{\mathrm{eNO}}$ is a marker of an allergic asthma phenotype, characterised by elevations in type 2 cytokines IL-4, IL-5 and IL-13 and eosinophils in sputum, serum, and bronchial biopsy [25-27].

However, we found that this association between asthma and increased $F_{\mathrm{eNO}}$ was seen only when aeroallergen $\operatorname{IgE}$ was detected. In the absence of aeroallergen $\operatorname{IgE}$, the association between asthma and $F_{\mathrm{eNO}}$ was lost. Our results suggest that asthma is only associated with $F_{\mathrm{eNO}}$ in the presence of allergic sensitisation, and that $F_{\mathrm{eNO}}$ is more likely to indicate the presence of aeroallergen IgE. We found that $F_{\mathrm{eNO}}$ $>35 \mathrm{ppb}$ had a positive predictive value of only 35\% for the diagnosis of asthma, compared to a positive predictive value of $94 \%$ for the presence of aeroallergen IgE. Our findings contrast with a study of 1156 children in France, which found that non-atopic asthmatics had higher $F_{\text {eNO }}$ than non-atopic children without asthma: average $F_{\mathrm{eNO}} 13.4 \mathrm{ppb}$ in non-atopic children with asthma versus $10.6 \mathrm{ppb}$ in non-atopic children without asthma [28]. However, our findings are consistent with other birth cohorts, including one from the Netherlands, which observed higher $F_{\mathrm{eNO}}$ only among young adults with atopic asthma, defined as asthma plus allergic sensitisation with positive serum IgE against 10 common aeroallergens, but not non-atopic asthma [29]. The Isle of Wight birth cohort in England, UK, similarly found that atopy (measured by skin-prick testing) was associated with higher $F_{\mathrm{eNO}}$, while the level of $F_{\mathrm{eNO}}$ did not differ between non-atopic teens with and without asthma [30]. The authors concluded, as we do, that $F_{\mathrm{eNO}}$ is a biomarker for atopy rather than asthma.

Our study also confirmed the association between AR and higher $F_{\mathrm{eNO}}$ among adolescents, which has been well established among adults and children [31-35]. Similar to our findings in asthma, we found that this association between $\mathrm{AR}$ and $F_{\mathrm{eNO}}$ was observed only in the presence of aeroallergen IgE. Other studies have also found that those with atopy and rhinitis have higher $F_{\text {eNO }}$ than those with rhinitis but no atopy $[28,36,37]$. This same large cohort of 1156 children in France found that non-asthmatic atopic participants (as determined by skin-prick test to common allergens) with rhinitis had significantly higher $F_{\mathrm{eNO}}$ than non-atopic participants with rhinitis $(20.7 \pm 13$ versus $12.5 \pm 6.4 \mathrm{ppb})$ [28]. Likewise, in an adult population examining atopic participants identified by skin-prick testing, GRATZIou et al. [37] found that $F_{\text {eNO }}$ was significantly higher in atopic rhinitis than in those with non-atopic rhinitis $(13.3 \pm 1.3$ versus $5.8 \pm 1.2 \mathrm{ppb})$.

One explanation of our findings is that asthma in the setting of low aeroallergen IgE is mediated by a non-allergic inflammatory pathway. This distinct non-allergic asthma phenotype represents a subset of asthmatics that may have more severe and more difficult to control asthma $[38,39]$. Rather than allergic, type 2-mediated pathways, these non-atopic asthmatics may have neutrophilic airway inflammation [40]. This may be determined, in part, by genetic factors, and those with allergic and non-allergic asthma have distinct HLA haplotypes [41]. Environmental exposures such as particulate air pollution or childhood viral infections may also contribute to non-allergic asthma, in a process mediated through neutrophilic inflammation [42]. A similar neutrophilic process may be occurring in our participants with asthma or $\mathrm{AR}$ and no significant serum IgE.

We found that aeroallergen IgE is associated with elevated $F_{\mathrm{eNO}}$ even in the absence of asthma or AR. A few studies have similarly found that atopy is associated with $F_{\text {eNO }}$ regardless of symptoms. For example, both CHOI et al. [36] and FrankLin et al. [43] examined children with asthma and atopy and found that atopy increases $F_{\mathrm{eNO}}$ regardless of asthma diagnosis. This has been similarly observed among Pacific Islander adults, where positive skin-prick testing to house dust mite was associated with higher exhaled and nasal NO even in the absence of asthma symptoms [44]. In a study comparing asthmatic and healthy children, BARRETO et al. [45] found that even in those without respiratory symptoms, atopy (defined by skin-prick testing) and peripheral eosinophil count were associated with significantly higher $F_{\mathrm{eNO}}$ compared to those without atopy or eosinophilia. In a population of school children, VAN AMSTERDAM et al. [46] similarly found that allergic sensitisation was associated with higher $F_{\mathrm{eNO}}$ even in those without wheeze, although the association was significantly augmented in those with wheeze.

Our findings suggest that IgE is an important factor in the elevated $F_{\text {eNO }}$ observed in asthma and AR in adolescents. While the exact mechanism by which IgE may influence $F_{\mathrm{eNO}}$ is not entirely clear, the 
pathophysiology by which each are elevated in asthma and AR has been previously explored. IgE may increase $F_{\mathrm{eNO}}$ along with inflammatory cytokines inducing iNOS. In immediate hypersensitivity reactions, IgE cross-links to the FceR1 receptor on mast cells, resulting in mast cell degranulation, inflammatory cytokine release, and activation of inflammatory cells at sites sensitive to the inciting allergy. Local IgE-mediated mechanisms may explain the localised reactions in skin, nasal turbinates, airways, and gut in eczema, rhinitis, asthma, and food allergy, respectively. In allergic asthma and AR specifically, the inflammatory cytokines that occur as a result of IgE-FceR1 cross-linking may induce iNOS, resulting in the increased $F_{\text {eNO }}$ observed in $\mathrm{AR}$ and asthma [47, 48]. The upregulated eosinophils in type 2 inflammation of asthma and AR may also exert direct oxidative damage and promote the continued release of inflammatory cytokines that activate iNOS, increasing NO in exhaled air [28, 45, 49].

Our study is one of the largest studies conducted in a well-characterised adolescent age group that examines the associations of asthma, allergy and $\operatorname{IgE}$ with airway inflammation as measured by $F_{\mathrm{eNO}}$. However, we acknowledge limitations to this study. Specifically, this is a cross sectional study evaluating $F_{\text {eNO}}$, asthma and AR at a single time-point in adolescence. Asthma and AR vary widely in symptoms, severity and control, and so associations may change depending on different time-points in the disease trajectory. Additionally, steroid use may reduce $F_{\mathrm{eNO}}$ although we had similar findings when excluding participants with any steroid use within $72 \mathrm{~h}$ of testing. In addition, there were very few participants who had asthma or AR but no aeroallergen IgE. This may represent the fact that the majority of those with asthma or AR in this study had an allergic asthma phenotype. There were, however, a large portion of our participants (36\%) who did not have asthma or AR but who did have aeroallergen IgE. Finally, we did not include those with previous or non-active asthma for those without wheeze in the last 12 months. Similarly, we did not include IgE positivity to non-tested allergens such as food-specific IgE. Future work may include these other allergens. We would also explore the comparison of $F_{\mathrm{eNO}}$ with blood eosinophils as a more widely available biomarker than $F_{\mathrm{eNO}}$.

Our study confirms the expected pattern of $F_{\mathrm{eNO}}$ elevation among adolescents with asthma and AR and implicates IgE-mediated pathways in the association between asthma, AR and $F_{\text {eNO}}$. Our findings suggest that the presence of aeroallergen IgE was critical to the $F_{\mathrm{eNO}}$ elevations observed in those with asthma or AR. Without aeroallergen IgE, that relationship was lost. Aeroallergen IgE can be considered a marker for elevated $F_{\mathrm{eNO}}$, since $F_{\mathrm{eNO}}$ was detected whenever aeroallergen IgE was present, regardless of the presence of clinical disease. Furthermore, even if $F_{\mathrm{eNO}}$ is elevated, it does not necessarily indicate asthma or AR, and patients with asthma and no aeroallergen IgE may not have an elevated $F_{\text {eNO}}$. Therefore, this study places $F_{\mathrm{eNO}}$ into perspective as a marker predominantly for sensitisation rather than for clinical disease, and further raises the need to identify alternative markers for airway inflammation in those children and adolescents with non-IgE-mediated asthma or AR.

Author contributions: B.M. Flashner drafted the manuscript. M.B. Rice contributed to the drafting and revision of the manuscript. S.L. Rifas-Shiman conducted the analyses. E. Oken, C.A. Camargo Jr, T.A.E. Platts-Mills, L. Workman, A.A. Litonjua and D.R. Gold contributed to the revision of the manuscript.

Support statement: This work was supported by the US National Institutes of Health (K23ES026204, R01 HD034568, R01AI102960, UH3OD023286), the American Thoracic Society Foundation and the American Lung Association. Funding information for this article has been deposited with the Crossref Funder Registry.

Conflict of interest: B.M. Flashner has nothing to disclose. S.L. Rifas-Shiman reports grants from the US National Institutes of Health during the conduct of the study. E. Oken reports grants from the US National Institutes of Health during the conduct of the study. C.A. Camargo Jr has nothing to disclose. T.A.E. Platts-Mills has nothing to disclose. L. Workman has nothing to disclose. A.A. Litonjua has nothing to disclose. D.R. Gold reports grants from the US National Institutes of Health during the conduct of the study. M.B. Rice reports grants from the US National Institutes of Health during the conduct of the study.

\section{References}

1 Dweik RA, Boggs PB, Erzurum SC, et al. An official ATS clinical practice guideline: interpretation of exhaled nitric oxide levels (FENO) for clinical applications. Am J Respir Crit Care Med 2011; 184: 602-615.

2 Leynaert B, Neukirch C, Liard R, et al. Quality of life in allergic rhinitis and asthma: a population-based study of young adults. Am J Respir Crit Care Med 2000; 162: 1391-1396.

3 Guerra S, Sherrill DL, Martinez FD, et al. Rhinitis as an independent risk factor for adult-onset asthma. J Allergy Clin Immunol 2002; 109: 419-425.

4 Settipane RJ, Hagy GW, Settipane GA. Long-term risk factors for developing asthma and allergic rhinitis: a 23year follow-up study of college students. Allergy Proc 1994; 15: 21-25.

5 Leynaert B, Bousquet J, Neukirch C, et al. Perennial rhinitis: an independent risk factor for asthma in nonatopic subjects: results from the European Community Respiratory Health Survey. J Allergy Clin Immunol 1999; 104: 301-304.

6 Linneberg A, Henrik Nielsen N, Frølund L, et al. The link between allergic rhinitis and allergic asthma: a prospective population-based study. The Copenhagen Allergy Study. Allergy 2002; 57: 1048-1052. 
Huovinen E, Kaprio J, Laitinen LA, et al. Incidence and prevalence of asthma among adult Finnish men and women of the Finnish Twin Cohort from 1975 to 1990, and their relation to hay fever and chronic bronchitis. Chest 1999; 115: 928-936.

8 Barnes PJ, Liew FY. Nitric oxide and asthmatic inflammation. Immunol Today 1995; 16: 128-130.

9 Duong-Quy S. Clinical utility of the exhaled nitric oxide (NO) measurement with portable devices in the management of allergic airway inflammation and asthma. J Asthma Allergy 2019; 12: 331-341.

10 Silvestri M, Spallarossa D, Frangova Yourukova V, et al. Orally exhaled nitric oxide levels are related to the degree of blood eosinophilia in atopic children with mild-intermittent asthma. Eur Respir J 1999; 13: 321-326.

11 Gandhi NA, Bennett BL, Graham NMH, et al. Targeting key proximal drivers of type 2 inflammation in disease. Nat Rev Drug Discov 2016; 15: 35-50.

12 Togias A. Rhinitis and asthma: evidence for respiratory system integration. J Allergy Clin Immunol 2003; 111: 1171-1183.

13 Feng $\mathrm{CH}$, Miller MD, Simon RA. The united allergic airway: connections between allergic rhinitis, asthma, and chronic sinusitis. Am J Rhinol Allergy 2012; 26: 187-190.

14 Cardenas A, Sordillo JE, Rifas-Shiman SL, et al. The nasal methylome as a biomarker of asthma and airway inflammation in children. Nat Commun 2019; 10: 3095.

15 Kim HB, Eckel SP, Kim JH, et al. Exhaled NO: determinants and clinical application in children with allergic airway disease. Allergy Asthma Immunol Res 2016; 8: 12-21.

16 Olin AC, Alving K, Torén K. Exhaled nitric oxide: relation to sensitisation and respiratory symptoms. Clin Exp Allergy 2004; 34: 221-226.

17 Oken E, Baccarelli AA, Gold DR, et al. Cohort profile: project viva. Int J Epidemiol 2015; 44: 37-48.

18 Asher MI, Keil U, Anderson HR, et al. International Study of Asthma and Allergies in Childhood (ISAAC): rationale and methods. Eur Respir J 1995; 8: 483-491.

19 Wilson JM, Workman L, Schuyler AJ, et al. Allergen sensitisation in a birth cohort at midchildhood: Focus on food component IgE and IgG4 responses. J Allergy Clin Immunol 2018; 141: 419-423.e5.

20 Peng C, Cardenas A, Rifas-Shiman SL, et al. Epigenome-wide association study of total serum immunoglobulin E in children: A life course approach. Clin Epigenetics 2018; 10: 55.

21 Khalili B, Boggs PB, Bahna SL. Reliability of a new hand-held device for the measurement of exhaled nitric oxide. Allergy 2007; 62: 1171-1174.

22 Menou A, Babeanu D, Paruit HN, et al. Normal values of offline exhaled and nasal nitric oxide in healthy children and teens using chemiluminescence. J Breath Res 2017; 11: 36008.

23 Alving K, Janson C, Nordvall L. Performance of a new hand-held device for exhaled nitric oxide measurement in adults and children. Respir Res 2006; 7: 67.

24 Sordillo JE, Webb T, Kwan D, et al. Allergen exposure modifies the relation of sensitisation to fraction of exhaled nitric oxide levels in children at risk for allergy and asthma. J Allergy Clin Immunol 2011; 127: 1165-1172.e5.

25 Strunk RC, Szefler SJ, Phillips BR, et al. Relationship of exhaled nitric oxide to clinical and inflammatory markers of persistent asthma in children. J Allergy Clin Immunol 2003; 112: 883-892.

26 Bettiol J, Bartsch P, Louis R, et al. Cytokine production from peripheral whole blood in atopic and nonatopic asthmatics: relationship with blood and sputum eosinophilia and serum IgE levels. Allergy 2000; 55 $1134-1141$

27 Lemière $\mathrm{C}$, Ernst $\mathrm{P}$, Olivenstein $\mathrm{R}$, et al. Airway inflammation assessed by invasive and noninvasive means in severe asthma: Eosinophilic and noneosinophilic phenotypes. J Allergy Clin Immunol 2006; 118: 1033-1039.

28 Jouaville LF, Annesi-Maesano I, Nguyen LT, et al. Interrelationships among asthma, atopy, rhinitis and exhaled nitric oxide in a population-based sample of children. Clin Exp Allergy 2003; 33: 1506-1511.

29 van Asch CJJ, Balemans WAF, Rovers MM, et al. Atopic disease and exhaled nitric oxide in an unselected population of young adults. Ann Allergy, Asthma Immunol 2008; 100: 59-65.

30 Scott M, Raza A, Karmaus W, et al. Influence of atopy and asthma on exhaled nitric oxide in an unselected birth cohort study. Thorax 2010; 65: 258-262.

31 Kharitonov SA, Rajakulasingam K, O'Connor B, et al. Nasal nitric oxide is increased in patients with asthma and allergic rhinitis and may be modulated by nasal glucocorticoids. J Allergy Clin Immunol 1997; 99: 58-64.

32 Arnal JF, Didier A, Rami J, et al. Nasal nitric oxide is increased in allergic rhinitis. Clin Exp Allergy 1997; 27: 358-362.

33 Martin U, Bryden K, Devoy M, et al. Increased levels of exhaled nitric oxide during nasal and oral breathing in subjects with seasonal rhinitis. J Allergy Clin Immunol 1996; 97: 768-772.

34 Henriksen AH, Sue-Chu M, Holmen TL, et al. Exhaled and nasal NO levels in allergic rhinitis: relation to sensitisation, pollen season and bronchial hyperresponsiveness. Eur Respir J 1999; 13: 301-306.

35 Cardinale F, de Benedictis FM, Muggeo V, et al. Exhaled nitric oxide, total serum IgE and allergic sensitisation in childhood asthma and allergic rhinitis. Pediatr Allergy Immunol 2005; 16: 236-242.

36 Choi BS, Kim KW, Lee YJ, et al. Exhaled nitric oxide is associated with allergic inflammation in children J Korean Med Sci 2011; 26: 1265-1269.

37 Gratziou C, Lignos M, Dassiou M, et al. Influence of atopy on exhaled nitric oxide in patients with stable asthma and rhinitis. Eur Respir J 1999; 14: 897-901.

38 Peters SP. Asthma phenotypes: nonallergic (Intrinsic) asthma. J Allergy Clin Immunol Pract 2014; 2: 650-652.

39 Hekking PPW, Bel EH. Developing and emerging clinical asthma phenotypes. J Allergy Clin Immunol Pract 2014; 2: 671-680.

40 Drews AC, Pizzichini MMM, Pizzichini E, et al. Neutrophilic airway inflammation is a main feature of induced sputum in nonatopic asthmatic children. Allergy 2009; 64: 1597-1601.

41 Takejima P, Agondi RC, Rodrigues $\mathrm{H}$, et al. Allergic and nonallergic asthma have distinct phenotypic and genotypic features. Int Arch Allergy Immunol 2017; 172: 150-160.

42 Douwes J, Gibson P, Pekkanen J, et al. Non-eosinophilic asthma: importance and possible mechanisms. Thorax 2002; 57: 643-648

43 Franklin PJ, Turner SW, Le Souëf PN, et al. Exhaled nitric oxide and asthma: complex interactions between atopy, airway responsiveness, and symptoms in a community population of children. Thorax 2003; 58: 1048-1052. 
44 Moody A, Fergusson W, Wells A, et al. Increased nitric oxide production in the respiratory tract in asymptomatic Pacific Islanders: an association with skin prick reactivity to house dust mite. J Allergy Clin Immunol 2000; 105 895-899.

45 Barreto M, Villa MP, Monti F, et al. Additive effect of eosinophilia and atopy on exhaled nitric oxide levels in children with or without a history of respiratory symptoms. Pediatr Allergy Immunol 2005; 16: 52-58.

46 van Amsterdam JGC, Janssen NAH, de Meer G, et al. The relationship between exhaled nitric oxide and allergic sensitisation in a random sample of school children. Clin Exp Allergy 2003; 33: 187-191.

47 Gould HJ, Sutton BJ, Beavil AJ, et al. The biology of IgE and the basis of allergic disease. Annu Rev Immunol 2003; 21: 579-628.

48 Kraft S, Kinet JP. New developments in FceRI regulation, function and inhibition. Nat Rev Immunol 2007; 7: 365-378.

49 Thomassen MJ, Raychaudhuri B, Dweik RA, et al. Nitric oxide regulation of asthmatic airway inflammation with segmental allergen challenge. J Allergy Clin Immunol 1999; 104: 1174-1182. 